\title{
Return-to-work intentions during spinal cord injury rehabilitation: an audit of employment outcomes
}

\author{
P Kennedy ${ }^{1,2}$ and L Hasson ${ }^{1}$
}

Study design: Single-centre, retrospective cohort study.

Objectives: To analyse the return-to-work intentions during spinal cord injury (SCI) rehabilitation.

Setting: Tertiary care, spinal cord injury rehabilitation unit, National Spinal Injuries Centre, Stoke Mandeville Hospital, Ayelsbury, UK. Methods: Employment outcomes were obtained from the Needs Assessment Checklist (NAC), for all patients admitted to the unit between February 2008 and October 2014. NAC1 is completed within 4 weeks post-mobilisation and NAC2 upon the patient moving to the pre-discharge ward. Data from 362 participants were analysed for return-to-work intentions, by gender, age and injury severity. Results: Seventy-six percent of the sample population was employed at the time of their injury. At NAC1, 22.4\% of individuals had made plans to return to work, whereas $44.2 \%$ had not; at NAC2, 34.3\% had made plans to return to work and $31.2 \%$ had not. This difference was found to be statistically significant. There were significant differences in return-to-work intentions by injury severity at NAC1 but not NAC2, and by age group at NAC2 but not NAC1.

Conclusion: Less than half of those employed at the time of their injury had made plans to return to work before their discharge from the unit. The low proportion of individuals with SCl returning to work-just one in three-is concerning in view of the lost health and psychosocial benefits, and requires greater prominence during rehabilitation. Future research into effective employment interventions to improve employment outcomes in this population is required.

Spinal Cord (2016) 54, 141-144; doi:10.1038/sc.2015.122; published online 21 July 2015

\section{INTRODUCTION}

It is well-established that one of the best indicators of effective rehabilitation following spinal cord injury (SCI) is a successful return to employment. ${ }^{1,2}$ Ludwig Guttmann, ${ }^{3}$ one of the pioneers of SCI rehabilitation, said in 1964: 'It is not the money, it is the realisation that regular work is important for their well-being: the most healthy of my paraplegics are those who have been in full-time employment for many years'. Yet despite a significant improvement in the quality of rehabilitative services, and a vast amount of research on this topic, 50 years later unemployment remains a critical issue for individuals with spinal injuries. ${ }^{4,5}$ The lack of intention for those with SCI to return to work gives cause for major concern, as both the physical and psychological health benefits, and improved quality and duration of life post-injury, are well documented advantages of resuming employment. ${ }^{1,6}$

Not only has there not been an increase in the proportion of individuals with SCI gaining employment after rehabilitation, as one might expect given the awareness of this issue and the well-established benefits of doing so, but the percentage of people returning to work post-injury may have actually decreased over the years. Guttmann ${ }^{7}$ reported in 1954 that $69 \%$ of 752 paraplegics were employed, with $78 \%$ of these working full-time. In the same year, Donald Munro ${ }^{8}$ working in USA, found that (from his original sample of 291), of those who were of appropriate working age and physically fit enough to work, $68.5 \%$ were employed. In contrast to this, a recent study reviewed 60 articles looking at employment in SCI and found an average employment rate of $35 \%$ following SCI ${ }^{1}$ (although rates varied significantly from 12 to $71 \%$ depending on the specific parameters of the study). Their own analysis of the National Spinal Cord Injury Statistical Center (NSCISC) database showed that $32.4 \%$ of paraplegics were employed 10 years post-injury. Chapin and Kewman ${ }^{9}$ stated that: 'the employment rate increases steadily and peaks at 30 to $35 \%$ at about 10 to 15 years after injury'. Similar results have been found in UK samples, where $32-38 \%$ of individuals with SCI were employed post-discharge. ${ }^{10,11}$ Given the development of new medical technologies, and the improved understanding and management of SCI-related secondary health complications, it is both disappointing and disconcerting that only one-third of patients return to work following rehabilitation.

Employment and money-related issues are some of the areas with the lowest reported satisfaction for individuals with SCI, and when it comes to life satisfaction, employment is an even more important factor than the level of impairment or disability. ${ }^{1}$ The benefits of employment following SCI rehabilitation are well documented and wide-ranging. Being employed is related to greater life satisfaction, better psychological adjustment and improved quality of life, ${ }^{1,12,13}$ as well as fewer secondary health complications ${ }^{14}$ and increased life expectancy. ${ }^{15}$ The financial independence (either full or part) resulting

${ }^{1}$ Department of Clinical Psychology, The National Spinal Injuries Centre, Stoke Mandeville Hospital, Aylesbury, UK and ${ }^{2}$ Oxford Institute of Clinical Psychology Training, University of Oxford, Oxford, UK

Correspondence: Professor P Kennedy, Department of Clinical Psychology, The National Spinal Injuries Centre, Stoke Mandeville Hospital, Mandeville Road, Aylesbury HP21 8AL, UK

E-mail: paul.kennedy@hmc.ox.ac.uk

Received 13 April 2015; revised 4 June 2015; accepted 15 June 2015; published online 21 July 2015 
from employment also contributes to a feeling of personal growth and an increased sense of purpose, ${ }^{9}$ and purpose in life has been shown to be directly related to positive psychological adaptation following SCI. ${ }^{16}$ It is evident that being able to maintain employment following SCI is a strong overall indicator of successful rehabilitation, owing to the levels of physical and psychological health and mobility, and effective skin, bladder and bowel management required to sustain work.

A number of factors have been repeatedly identified as being crucial predictors for returning to work following SCI. One of the factors most consistently associated with employment following SCI is preinjury education level, those individuals with higher levels of education were significantly more likely to return to work following rehabilitation. ${ }^{2,17}$ Similarly consistent is the factor of age at injury, with those who are younger at the time of their injury significantly more likely to gain employment post-injury than those who are older. $^{2,17}$ Another significant predictor of employment post-SCI is ethnicity, where disparities are well-established. ${ }^{17}$ Arango-Lasprilla et al. ${ }^{18}$ found that, once age, gender, marital status, education level, employment status at admission, cause of injury and ASIA impairment scale were all controlled for, ethnicity still significantly affected employment status at 1-year post-SCI, with the odds of unemployment nearly twice as high for Hispanics than for Caucasians. Factors such as gender, marital status and level of injury have been found to be inconclusive predictors for returning to work following SCI, with some studies showing that they significantly predict employment whereas other research suggests they do not. ${ }^{1}$ Returning to work for the pre-injury employer is one of the most significant factors relating to both employment following SCI and time taken to return to work. ${ }^{19,20}$ Studies have found that a 'fast track' exists whereby individuals with SCI who return to work for their pre-injury company, whether in the same role or a new role, return to work significantly

Table 1 Participant demographics

\begin{tabular}{|c|c|}
\hline \multicolumn{2}{|l|}{$\operatorname{Sex}(\%)$} \\
\hline Male & $281(77.6)$ \\
\hline Female & $81(22.4)$ \\
\hline \multicolumn{2}{|l|}{ Age at NAC1 } \\
\hline Mean (s.d.) & $40.26(13.5)$ \\
\hline Range & 16-65 years \\
\hline \multicolumn{2}{|l|}{ Age groups (years) } \\
\hline $16-30$ & $104(28.7 \%)$ \\
\hline $31-45$ & $125(34.5 \%)$ \\
\hline $46-65$ & $133(36.7 \%)$ \\
\hline \multicolumn{2}{|l|}{ Severity of injury (\%) } \\
\hline C1-4 AIS A-C & $51(14.1)$ \\
\hline C5-8 AIS A-C & $57(15.7)$ \\
\hline T1-S5 AIS A-C & $167(46.1)$ \\
\hline AIS D & $56(15.5)$ \\
\hline Missing & $31(8.6)$ \\
\hline \multicolumn{2}{|l|}{ Cause of injury (\%) } \\
\hline Road traffic accident & $120(33.1)$ \\
\hline Fall & $73(20.2)$ \\
\hline Sports injury & $41(11.3)$ \\
\hline Non-traumatic & $111(30.7)$ \\
\hline Other & $17(4.7)$ \\
\hline
\end{tabular}

Abbreviations: AIS, American Spinal Injury Association (ASIA) Impairment Scale; NAC, Needs Assessment Checklist. faster than those who find employment with a new company. This key piece of information should have a crucial role in future attempts to improve employment outcomes post-SCI.

In antithesis to the numerous factors which facilitate successful return to employment, there are a number of well-known 'barriers' to returning to work for people with spinal injuries. Physical factors such as bladder and bowel incontinence, pressure ulcers, fatigue and/or medical problems requiring re-hospitalisation are all potential health problems which can prevent an individual with SCI from sustaining employment. ${ }^{2}$ A lack of independence in mobility and not being able to drive were other factors identified as barriers to employment. Psychological and psychosocial barriers also exist, such as 'Most employers will not hire me because of my disability' or 'The types of jobs that I can do now just do not interest me'. ${ }^{6}$ These are complex issues which need to be appropriately addressed throughout the rehabilitation process if successful employment outcomes are to be achieved. Finally, the loss of financial benefits or welfare associated with disability (or in some cases accident compensation) is an economic barrier to employment for some people with SCI, who are disincentivised from returning to work as it might mean a loss of benefits. ${ }^{2,6}$

The concept of implementation intentions-plans which enhance the translation of goal intentions into actions-has been studied in the context of health behaviours by Gollwitzer and Sheeran. ${ }^{21,22}$ Research has found a significant association between participants' goal intentions and behavioural outcomes; however, one study found that people translated their good intentions into actions only $53 \%$ of the time. ${ }^{23}$ Although the strength of intentions varies, Gollwitzer and Sheeran ${ }^{22}$ conclude that 'forming even strong goal intentions does not guarantee goal attainment'. In the context of the current study, this suggests that, in some cases, even patients who have made plans to return to work during rehabilitation may not follow through with such plans following discharge.

The current study aims to explore the critical issue of employment for individuals with SCI. This study identifies the employment intentions in those undergoing active SCI rehabilitation, and discusses the need for future research to improve such outcomes.

\section{MATERIALS AND METHODS}

\section{Participants}

Data routinely collected from all individuals admitted to the spinal injuries unit between August 2008 and October 2014 were considered for this study. Only patients who met all of the following inclusion criteria were entered into the analysis:

- Both Needs Assessment Checklist (NAC) 1 and NAC2 completed and all employment data present and correct.

- Between the age of 16-65 years.

- Not retired.

In total, data from 362 individuals were used in the analysis. Participant demographics can be seen in Table 1. The demographics of the current sample population were deemed comparable to those of other UK cohorts of people with SCI. ${ }^{10,24}$

\section{Procedure}

The NAC is a comprehensive rehabilitation outcome measure designed specifically for individuals with SCI which has demonstrated good reliability and validity. ${ }^{25,26} \mathrm{NACl}$ is completed within 4 weeks post-mobilisation and $\mathrm{NAC2}$ is completed when the patient is moved into the pre-discharge ward. All data are entered onto a database and stored in accordance with Trust confidentiality guidelines. Data were analysed using SPSS 17.0 (SPSS, Chicago, 
IL, USA). Statistical tests used included the McNemar test for paired sample dichotomous data, $\chi^{2}$ tests for return-to-work outcomes by gender, injury severity and age groups, and a logistic regression analysis for age at NACl and dichotomous return-to-work outcomes.

\section{RESULTS}

Of the 362 participants, $275(76.0 \%)$ were employed at the time of their injury, whereas $84(23.2 \%)$ were unemployed and $3(0.8 \%)$ were self-employed.

One of the key questions which all participants answered at both NAC1 and NAC2 was: 'Have you made plans to return to work?' The results can be seen in Table 2. In addition to 'Yes' and 'No' options, participants could select 'Don't Know/Unsure' (if, for example, they had begun discussion with a previous employer who had suggested that they may be able to return to work there but had not finalised any plans or discussed details) or 'N/A' (Not Applicable, meaning that the participant considers employment not to be pertinent to them at that time, the reasons for which are to be explored by the authors in a future study).

A McNemar test (a significance test for paired sample dichotomous data) of 'Yes' and 'No' responses revealed a significant difference, $\chi^{2}(1, n=184)=21.97, P<0.001$. This suggests that return-to-work intentions are different at NAC1 and NAC2, in this case wherein there is a significant improvement over the course of rehabilitation (an increase in 'Yes' responses and a decrease in 'No' responses).

Chi-square tests showed no significant differences in return-to-work outcome between genders at either NAC1 or NAC2.

Chi-square tests showed a significant difference in return-to-work outcome by injury severity at NAC1, $\chi^{2}(9)=17.36, P=0.043$ (see Table 3), but no significant difference at NAC2.

Chi-square tests showed no significant difference in return-to-work outcome between age groups at NAC1. However, there were significant differences between age groups at NAC2, $\chi^{2}(6)=14.68$,

Table 2 Have you made plans to return to work?

\begin{tabular}{lrr}
\hline & \multicolumn{1}{c}{$N A C 1$} & \multicolumn{1}{c}{$N A C 2$} \\
\hline Yes & $81(22.4 \%)$ & $124(34.3 \%)$ \\
No & $160(44.2 \%)$ & $113(31.2 \%)$ \\
Don't Know/Unsure & $51(14.1 \%)$ & $52(14.4 \%)$ \\
N/A & $70(19.3 \%)$ & $73(20.2 \%)$ \\
\hline
\end{tabular}

Abbreviations: N/A, not applicable; NAC, Needs Assessment Checklist.

Table 3 Have you made plans to return to work? By injury severity at NAC1

\begin{tabular}{|c|c|c|c|c|}
\hline & \multicolumn{4}{|c|}{ Injury severity } \\
\hline & C1-4 & C5-8 & T1-S5 & \\
\hline & AIS A-C & AIS A-C & AIS A-C & AIS D \\
\hline \multirow[t]{2}{*}{ Yes } & 15 & 7 & 42 & 10 \\
\hline & $29.40 \%$ & $12.30 \%$ & $25.10 \%$ & $17.90 \%$ \\
\hline \multirow[t]{2}{*}{ No } & 15 & 37 & 70 & 25 \\
\hline & $29.40 \%$ & $64.90 \%$ & $41.90 \%$ & $44.60 \%$ \\
\hline \multirow[t]{2}{*}{ Don't Know } & 9 & 4 & 26 & 8 \\
\hline & $17.60 \%$ & $7.00 \%$ & $15.60 \%$ & $14.30 \%$ \\
\hline \multirow[t]{2}{*}{$\mathrm{N} / \mathrm{A}$} & 12 & 9 & 29 & 13 \\
\hline & $23.50 \%$ & $15.80 \%$ & $17.40 \%$ & $23.20 \%$ \\
\hline
\end{tabular}

Abbreviations: AIS, American Spinal Injury Association (ASIA) Impairment Scale; N/A, not applicable; NAC, Needs Assessment Checklist.
$P=0.023$ (see Table 4). Logistic regression analyses of dichotomous return-to-work outcomes at both NAC1 and NAC2 using age at $\mathrm{NAC1}$ as a predictor variable were non-significant.

\section{DISCUSSION}

The results show that $34.3 \%$ of individuals in rehabilitation had made plans to return to work at NAC2. This figure is very consistent with previous research which has found the employment rate post-SCI to be $30-35 \%$. This figure is also highly congruent with the findings of Kennedy et al., ${ }^{11}$ whose Community Needs study followed-up a similar cohort 3-18 months after discharge and found that $32 \%$ of participants were employed. This suggests that the Needs Assessment Checklist is a reliable measure of post-rehabilitation outcomes.

The results show that, although the number of 'Don't Know/Unsure' and 'N/A' answers remained relatively stable from $\mathrm{NAC} 1$ to NAC2, there was a significant increase in the number of 'Yes' answers and decrease in the number of 'No' answers, to the point where 'Yes' overtook 'No' in NAC2. This encouraging trend suggests that some patients are supported and assisted in making plans to return to work during their rehabilitation. Despite this, the overall proportion of patients who have made plans to return to employment by NAC2 is still just one in three, that is, less than half the number who were employed at the time of their injury.

The results showed no significant differences in return-to-work intentions by gender. Previous research on this topic has been inconclusive; Ottomanelli and Lind ${ }^{1}$ report that some studies have found males to be more likely to return to work following SCI, whereas other studies have found females to be more likely, and some research has found no difference. Whilst the current study found significant differences in return-to-work intentions by injury severity at NAC1, the results may have been affected by low sample size, a limitation which is supported by the lack of any significant difference at NAC2. Some studies have found a relationship between severity of injury and employment, ${ }^{27,28}$ whereas other studies have found no significant association. ${ }^{29}$ However, it should be noted that a well-established discrepancy exists wherein persons with paraplegia are more likely to be employed than those with tetraplegia. ${ }^{30}$

The results show that all age groups had 'Yes' rates of 33-35\% by $\mathrm{NAC2}$, in keeping with previous research. However, the reasons for having not made plans to return to work were more varied. 'No' rates varied drastically from $21 \%$ in the youngest group to $40 \%$ in the 31-45 years age group. Conversely, this age group had the lowest 'N/A' response, just $14.4 \%$ in comparison with the youngest group where $28.8 \%$ of patients said that employment was 'Not Applicable' to them

\section{Table 4 Have you made plans to return to work? By age group at} NAC2

\begin{tabular}{lccc}
\hline & \multicolumn{3}{c}{ Age group (years) } \\
\cline { 2 - 4 } & $16-30$ & $31-45$ & $46-65$ \\
\hline Yes & 35 & 44 & 45 \\
& $33.70 \%$ & $35.20 \%$ & $33.80 \%$ \\
No & 22 & 50 & 41 \\
Don't Know & $21.20 \%$ & $40.00 \%$ & $30.80 \%$ \\
& 17 & 13 & 22 \\
N/A & $16.30 \%$ & $10.40 \%$ & $16.50 \%$ \\
& 30 & 18 & 25 \\
& $28.80 \%$ & $14.40 \%$ & $18.80 \%$ \\
\hline
\end{tabular}

Abbreviations: N/A, not applicable; NAC, Needs Assessment Checklist. 
at NAC2. Whilst there are significant differences here, small sample size limits the reliability and generalisability of these findings. It is also worth noting that, in general, the individuals in the younger groups have sustained more severe injuries than the older patients, as the younger people tend to have been involved in road transport accidents, sports injuries or assaults (and tend to be AIS A-C), whereas the older individuals are more likely to have been injured in a fall (and are more likely to be AIS D). This age/injury severity imbalance may go some way to explaining these results. Furthermore, the logistic regression analyses of return-to-work outcomes using age as a predictor variable were non-significant, which may also reflect small sample sizes. In light of these limitations, it is felt that further research is needed to elucidate the effect of age on employment outcomes in this cohort. There is a well-established relationship between age at injury and return to work in the literature, with those who are younger more likely to successfully gain employment following SCI. ${ }^{2,17}$ This conclusion should inform rehabilitative staff that certain age groups such as older adults may require greater support for them to return to work post-discharge.

With regards to gender, age and injury severity, the results remain largely inconclusive. These factors should be the subject of further community-based studies. This will help shape intervention strategies and improve employment-related outcomes following rehabilitation.

\section{Clinical implications and future research}

This study has highlighted the low percentage of individuals who plan to return to employment following SCI. This figure-just one in three -is well documented in the literature, and a consistency has been found between employment intentions measured during rehabilitation and actual community surveys of a similar cohort post-discharge. There are a number of factors which potentially affect return-to-work outcomes, including pre-injury education level, age at injury, ethnicity and injury severity, as well as physical and psychosocial factors. There are wide-ranging benefits to regaining employment following SCI, including financial, physical, social and psychological advantages. ${ }^{31}$

In order to improve the proportion of individuals who return to work after their injury, the authors recommend that rehabilitative staff address return-to-work issues earlier in the rehabilitation process, encourage patients to maintain active links with their pre-injury employers, emphasise the wide-ranging benefits of returning to work on both physical and mental health, as well as financial independence, and explore the provision of on-site employment/careers advisory services.

Future research is also critical in driving changes to employment outcomes post-rehabilitation. The authors of the current study plan to follow-up this cohort post-discharge with a comprehensive survey of employment outcomes, occupations, return-to-work times and a qualitative element examining individuals' feelings towards employment post-SCI. Further research could also explore the timing postinjury of targeted interventions in return to work programmes.

\section{DATA ARCHIVING}

There were no data to deposit.

\section{CONFLICT OF INTEREST}

The authors declare no conflict of interest.

\section{ACKNOWLEDGEMENTS}

We thank all patients and staff at the National Spinal Injuries Centre, Stoke Mandeville Hospital, who participated in this audit.
1 Ottomanelli L, Lind L. Review of critical factors related to employment after spinal cord injury: implications for research and vocational services. J Spinal Cord Med 2009; 32: 503-531.

2 Franceschini M, Pagliacci MC, Russo T, Felzani G, Aito S, Marini C et al. Occurrence and predictors of employment after traumatic spinal cord injury: the GISEM study. Spinal Cord 2012; 50: 238-242.

3 Guttmann L. Rehabilitation and the paraplegic. J Coll Gen Pract 1964; 8: 36-42.

4 Ottomanelli L, Sippel JL, Cipher DJ, Goetz LL. Factors associated with employment among veterans with spinal cord injury. J Vocat Rehabil 2011; 34: 141-150.

5 Frieden L, Winnegar AJ. Opportunities for research to improve employment for people with spinal cord injuries. Spinal Cord 2012; 50: 379-381.

6 Krause JS, Reed KS. Barriers and facilitators to employment after spinal cord injury: underlying dimensions and their relationship to labor force participation. Spinal Cord 2011; 49: 285-291.

7 Guttmann L. Statistical survey on one thousand paraplegics. Proc R Soc Med 1954; 47: 1099-1103.

8 Munro D. Rehabilitation of patients totally paralyzed below waist with special reference to making them ambulatory and capable of earning their own livings. $N$ Engl J Med 1954; 250: 4-14.

9 Chapin M, Kewman D. Factors affecting employment following spinal cord injury: a qualitative study. Rehabil Psychol 2001; 46: 400-416.

10 Kennedy P, Lude P, Taylor N. Quality of life, social participation, appraisals and coping post spinal cord injury: a review of four community samples. Spinal Cord 2006; 44: 95-105.

11 Kennedy P, Sherlock O, McClelland M, Short D, Royle J, Wilson C. A multi-centre study of the community needs of people with spinal cord injuries: the first 18 months. Spinal Cord 2010; 48: 15-20.

12 Krause JS, DeVivo MJ, Jackson AB. Health status, community integration, and economic risk factors for mortality after spinal cord injury. Arch Phys Med Rehabil 2004; 85: 1764-1773.

13 Anderson CJ, Vogel LC, Chlan KM, Betz RR, McDonald CM. Depression in adults who sustained spinal cord injuries as children or adolescents. J Spinal Cord Med 2007; 30: S76-S82.

14 Meade MA, Forchheimer MB, Krause JS, Charlifue S. The influence of secondary conditions on job acquisition and retention in adults with spinal cord injury. Arch Phys Med Rehabil 2011; 92: 425-432.

15 Krause JS, Saunders LL, Acuna J. Gainful employment and risk of mortality after spinal cord injury: effects beyond that of demographic, injury and socioeconomic factors. Spinal Cord 2012; 50: 784-788.

16 deRoon-Cassini TA, de St Aubin E, Valvano A, Hastings J, Horn P. Psychological well-being after spinal cord injury: perception of loss and meaning making. Rehabil Psychol 2009; 54: 306-314.

17 Krause JS, Terza JV, Erten M, Focht KL, Dismuke CE. Prediction of postinjury employment and percentage of time worked after spinal cord injury. Arch Phys Med Rehabil 2012; 93: 373-375.

18 Arango-Lasprilla JC, Ketchum JM, Stevens LF, Balcazar F, Wehman P, Forster L et al. Ethnicity/racial differences in employment outcomes following spinal cord injury. NeuroRehabilitation 2009; 24: 37-46.

19 Ramakrishnan K, Mazlan M, Julia PE, Abdul Latif L. Return to work after spinal cord injury: factors related to time to first job. Spinal Cord 2011; 49: 1-4.

20 Krause JS, Terza JV, Saunders LL, Dismuke CE. Delayed entry into employment after spinal cord injury: factors related to time to first job. Spinal Cord 2010; 48: 487-491.

21 Gollwitzer PM, Sheeran P. Implementation intentions and goal achievement: a meta-analysis of effects and processes. Adv Exp Soc Psychol 2006; 38: 69-119.

22 Gollwitzer PM, Sheeran P. National Cancer Institute Implementation intentions. Health Behavior Constructs: Theory, Measurement and Research 2008, Cancer control and population sciences: US National Institutes of Health. Available at http://cancercontrol. cancer.gov/brp/constructs/implementation_intentions/ii5.html. Accessed on 16 February 2015.

23 Sheeran P. Intention-behavior relations: a conceptual and empirical review In: Stroebe W, Hewstone M (eds). European Review of Social Psychology 2002, Wiley, Chichester, UK, pp 1-30.

24 Kennedy P, Lude P, Elfström ML, Smithson E. Appraisals, coping and adjustment pre and post SCl rehabilitation: a 2-year follow-up study. Spinal Cord 2012; 50: $112-118$.

25 Kennedy P, Hamilton LR. The needs assessment checklist: a clinical approach to measuring outcome. Spinal Cord 1999; 37: 136-139.

26 Berry C, Kennedy P. A psychometric analysis of the Needs Assessment Checklist (NAC). Spinal Cord 2003; 41: 490-501.

27 Pflaum C, McCollister G, Strauss DJ, Shavelle RM, DeVivo MJ. Worklife after traumatic spinal cord injury. J Spinal Cord Med 2006; 29: 377-386.

28 Krause JS, Terza JV. Injury and demographic factors predictive of disparities in earnings after spinal cord injury. Arch Phys Med Rehabil 2006; 87: 1318-1326.

29 Burnham RS, Warren SA, Saboe LA, Davis LA, Russell GG, Reid DC. Factors predicting employment 1 year after traumatic spine fracture. Spine 1996; 21: 1066-1101.

30 National Spinal Cord Injury Statistical Center. Spinal cord injury facts \& figures at a glance. J Spinal Cord Med 2008; 31: 357-358.

31 Meade MA, Reed KS, Saunders LL, Krause JS. It's all of the above: benefits of working for individuals with spinal cord injury. Top Spinal Cord Inj Rehabil 2015; 21: 1-9. 